\title{
NERACA KARBON, EMISI DAN SERAPAN HISTORIS CO2 KARENA PERUBAHAN PENGGUNAAN LAHAN DI KABUPATEN BANYUASIN, SUMATERA SELATAN
}

\author{
Carbon Balance, Emissions and Sequestration of $\mathrm{CO}_{2}$ Historically due to Land Use Changes \\ in Banyuasin Regency, South Sumatera
}

\author{
Firyadi $^{\mathrm{a}}$, Widiatmaka ${ }^{\mathrm{b}}$, Asdar Iswati $^{\mathrm{b}}$, Muhamad Ardiansyah $^{\mathrm{b}}$, Budi Mulyanto $^{\mathrm{b}}$ \\ ${ }^{a}$ Program Studi Ilmu Tanah, Sekolah Pascasarjana, Institut Pertanian Bogor, Kampus IPB Darmaga, Bogor 16680 \\ -plgfiryadi@yahoo.co.id \\ ${ }^{b}$ Departemen Ilmu Tanah dan Sumberdaya Lahan, Fakultas Pertanian, Institut Pertanian Bogor, Kampus IPB \\ Darmaga, Bogor 16680
}

\begin{abstract}
Land use change is the cause of carbon loss from land. The loss of this carbon becomes a source of carbon dioxide $\left(\mathrm{CO}_{2}\right)$ in the atmosphere that can cause global warming. Intensive land use and land cover occurred in Kabupaten Banyuasin from 2004 2014. The purpose of this study. to create carbon balance, emissions and sequestration of $\mathrm{CO}_{2}$ during the period of 2004 - 2014 in Banyuasin Regency caused by land use change and land cover change. The method used to create carbon balance using land use change matrix, carbon calculation of each carbon pool by allometric method, destructive sample and organic C by Walkley and Black method. Stock diference method for analysis of changes in carbon storage, $\mathrm{CO}_{2}$ emissions and $\mathrm{CO}_{2}$ sequestration. The results of this study indicate that the 2004-2014 carbon balance in Banyuasin Regency is negative, with a carbon loss of 22,033,277 tons with an average annual carbon loss of 2,203,327 tons. $\mathrm{CO}_{2}$ sequestration of 29,298,966 tons and $\mathrm{CO}_{2}$ emissions 118,044,141 tons, while net emissions 88,745,175 tons. Average net $\mathrm{CO}_{2}$ emissions from above ground carbon pools, carbon necromassa pools, litter carbon pools and underground carbon pools are 7 tonnes $\mathrm{ha}^{-1}$ year ${ }^{-1}$, whereas $\mathrm{CO}_{2}$ emissions from organic soil C 0.61 tonnes ha${ }^{1}$ year ${ }^{-1}$. The largest contributor of $\mathrm{CO}_{2}$ emissions in Banyuasin Regency are sequentially caused by changes in peat swamp forests, secondary mangrove forests, primary mangrove forests and secondary swamp forests. While the source of sequestration is the change of monoculture rubber peat, oil palm, rubber monoculture and shrubs.
\end{abstract}

Keywords: Carbon balance, $\mathrm{CO}_{2}$, emissions, land use change, sequestration.

(Diterima: 23-08-2017; Disetujui: 02-10-2017)

\section{Pendahuluan}

\subsection{Latar Belakang}

Perubahan penggunaan lahan merupakan penyebab kehilangan karbon dari wilayah terestrial dan telah menjadi sumber karbon dioksida $\left(\mathrm{CO}_{2}\right)$ atmosfer yang signifikan (Jiao et al., 2010; Singh et al., 2011; Wang et al., 2013). Berpindahnya karbon yang ada di daratan ke atmosfer terjadi melalui proses dekomposisi dan pembakaran karbon yang terjadi di daratan, sedangkan perpindahan karbon dalam bentuk $\mathrm{CO}_{2}$ ke daratan melalui proses fotosintesis. Pada proses fotosintesis vegetasi menangkap $\mathrm{CO}_{2}$ dari atmosfer yang selanjutnya akan dirubah menjadi biomassa. Menurut Lasco (2004) aliran berpindahnya karbon per tahun dari ekosistem daratan saat ini lebih banyak jumlahnya (diperkirakan sekitar $60 \mathrm{Pg}^{-1} \mathrm{C}$ ) jika dibandingkan dengan perpindahan karbon dari atmosfer ke ekosistem daratan (diperkirakan sebesar $0.7 \pm 1.0 \mathrm{Pg} \mathrm{C}$ ).

Adanya selisih jumlah yang besar antara karbon yang berpindah dari ekosistem darat ke atmosfer dibandingkan dengan karbon yang berpindah dari atmosfer ke ekosistem darat telah menyebabkan meningkatnya konsentrasi $\mathrm{CO}_{2}$ di atmosfer bumi.
Untuk mengetahui berapa besar perpindahan $\mathrm{CO}_{2}$ dari atmosfer ke daratan dan sebaliknya, perlu dilakukan kajian dengan menyusun neraca karbon. Disamping mengetahui jumlah $\mathrm{CO}_{2}$ yang dilepaskan (emisi) dan yang ditangkap vegetasi (serapan), hal lain yang tidak kala pentingnya untuk melihat status karbon di suatu wilayah adalah jumlah tampungan karbon totalnya. Angka simpanan total karbon dalam satu wilayah dapat dijadikan dasar penilaian yang objektif untuk menentukan besar kecilnya emisi dan serapan yang terjadi,karena akan dibandingkan dengan jumlah tampungan karbon total yang dimiliki suatu wilayah.

Untuk dapat menilai perubahan simpanan karbon yang terjadi pada sistem terestrial daratan, IPCC (1997) membagi karbon kedalam 5 (lima) tampungan. Yaitu tampungan karbon di atas permukaan tanah, tampungan karbon di dalam tanah, tampungan karbon nekromasa, tampungan karbon serasah dan tampungan C organik tanah.

Dalam pengukuran simpanan karbon masing-masing tampungan prinsipnya adalah, jumlah biomassa pada suatu lahan dapat menggambarkan banyaknya $\mathrm{CO}_{2}$ di atmosfer yang diserap oleh tanaman. Sedangkan pengukuran $\mathrm{C}$ yang masih tersimpan dalam bagian tumbuhan yang telah mati (nekromasa) secara tidak langsung menggambarkan $\mathrm{CO}_{2}$ yang tidak dilepaskan 
ke udara lewat pembakaran (Hairiah et al., 2004; Lai 2008). Sequester C dalam tanah dapat juga dihitung berdasarkan input $\mathrm{C}$ dari sisa tanaman dan sumber lain dibandingkan dengan jumlah pelepasan $\mathrm{C}$ menjadi $\mathrm{CO}_{2}$. Jadi jumlah bersih serapan $\mathrm{C}$ sama dengan besarnya input $\mathrm{C}$ ( sisa tanaman) dikurangi output $\mathrm{C}$ (pelepasan $\mathrm{C}$ dari ekosistem daratan sebagai $\mathrm{CO}_{2}$ ) dengan asumsi kehilangan akibat erosi dan pencucian diabaikan (Duiker dan Lal, 2000)

Neraca karbon akan menggambarkan jumlah emisi dan serapan total $\mathrm{CO}_{2}$ dalam suatu wilayah, namun juga dapat menggambarkan sumber-sumber utama perubahan penggunaan lahan yang menghasilkan emisi dan sumber-sumber perubahan penggunaan lahan yaang menghasilkan serapan. Neraca karbon yang terbentuk di Kabupaten Banyuasin nantinya akan bermanfaat dalam menentukan upaya pengendalian emisi $\mathrm{CO}_{2}$ yang disebabkan oleh perubahan penggunaan lahan.

Mekipun perubahan penggunaan lahan diyakini telah menyumbang sepertiga dari peningkatan konsentrasi $\mathrm{CO}_{2}$ di atmosfer secara global, namum jumlah $\mathrm{CO}_{2}$ yang dilepaskan ke atmosfer tentunya akan berbeda-beda di masing-masing wilayah. Hal ini disebabkan oleh berbeda-bedanya perubahan penggunaan lahan yang terjadi di tiap-tiap wilayah.

Kabupaten Banyuasin merupakan wilayah yang perubahan penggunaan lahannya cukup intensif terjadi antara tahun 2004-2014, sehingga menjadi menarik untuk mengetahui neraca karbon, emisi dan sekuestrasi $\mathrm{CO}_{2}$. Di samping itu Kabupaten Banyuasin juga memiliki tipe penggunaan yang sangat beragam dan luas wilayah yang cukup luas $(1,281,555 \mathrm{ha})$.

Perubahan karbon pada masing-masing tampungan karbon yang disebabkan oleh perubahan penggunaan lahan dapat dijadikan acuan dalam penyusunan rencana penggunaan/penutupan lahan yang ada di rencana tata ruang wilayah. Berbagai alternatif perubahan penggunaan lahan dengan tingkat kehilangan karbon tertentu akan diketahui ketika rencana tata ruang wilayah disusun. Hal ini akan sangat membantu bagi suatu wilayah untuk memilih rencana tata ruang yang rendah kehilangan karbon, bahkan rencana tata ruang wilayah yang dapat menyebabkan bertambahnya tampungan karbon ke ekosistem darat sebelum rencana tata ruang wilayah ditetapkan.

Kegunaan lain dari hasil penelitian ini adalah menghasilkan nilai tampungan karbon penggunaan lahan yang telah disesuaikan dengan klasifikasi berdasarkan tampungan karbon. Nilai tampungan ini tentunya dapat juga dimanfaatkan untuk mengevaluasi tampungan karbon dan perubahan tampungan karbon karena perubahanan penggunaan lahan di wilayah lain, tanpa melakukan penghitungan ulang tampungan karbon masing-masing penggunaan lahan.

\subsection{Tujuan}

Penelitian ini bertujuan untuk menyusun neraca karbon, menduga emisi dan serapan $\mathrm{CO}_{2}$ di Kabupaten Banyuasin, Provinsi Sumatera Selatan selama tahun
2004-2014 yang disebabkan oleh perubahan penggunaan lahan.

\section{Metode Penelitian}

\subsection{Tempat dan Waktu}

Penelitian dilaksanakan di wilayah Kabupaten Banyuasin Provinsi Sumatera Selatan dengan waktu penelitian selama delapan bulan, yaitu bulan Juni 2015 sampai dengan bulan Februari 2016. Penelitian ini terdiri dari kegiatan pemetaan dan ground check penggunaan lahan tahun 2014 dan pengukuran simpanan karbon. Wilayah penelitian sebagaimana Gambar 1.

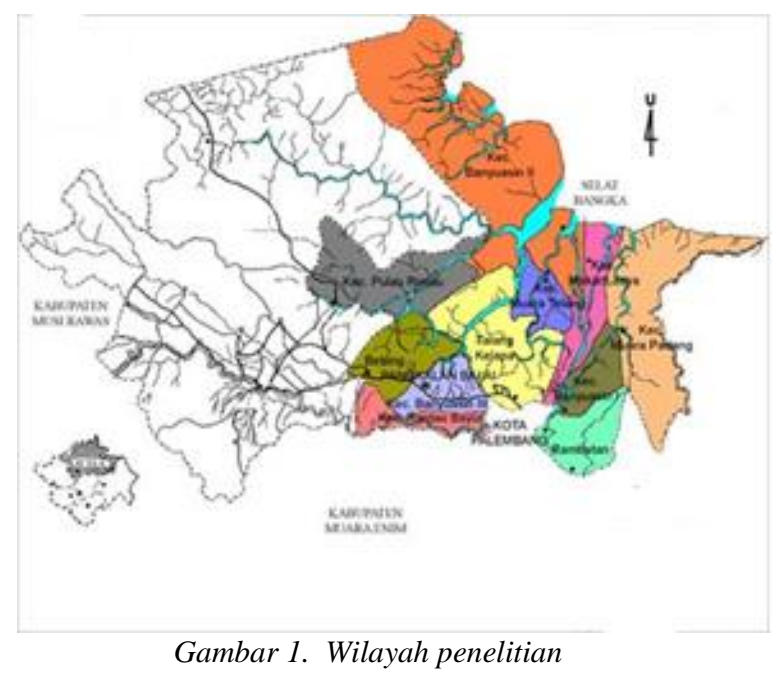

\subsection{Bahan dan Alat}

Bahan yang digunakan dalam penelitian ini berupa data sekunder dan data primer. Data sekunder Citra Spot 5 tahun 2004, Citra Spot 5 tahun 2009 dan Spot 6 tahun 2014. Disamping itu juga digunakan data Peta Neraca Tata Guna Tanah skala 1:25,000 Kabupaten Banyuasin tahun 2014 yang merupakan hasil pemetaan yang dilakukan oleh Kantor Wilayah Badan Pertanahan Nasional Provinsi Sumatera Selatan. Data sekunder lainnya berupa peta Jenis Tanah Kabupaten Banyuasin skala 1 : 25,000, Peta Curah Hujan, Peta Kemiringan dan Peta Administrasi. Data Primer berupa hasil penghitungan biomassa masing-masing tipe penggunaan lahan. Pengumpulan data di lapangan, meliputi cadangan $\mathrm{C}$ pada tampungan di atas permukaan tanah, tampungan nekromasa, tampungan serasah, tampungan di bawah tanah dan tampungan $\mathrm{C}$ organik tanah.

Alat yang digunakan dalam penelitian ini adalah seperangkat komputer yang dilengkapi dengan software Arc View 3.3, Software ER Mapper 7.0.,Microsoft Excel, Word. Peralatan lainnya yang digunakan pada saat pengumpulan data lapangan adalah GPS, kamera digital, timbangan, alat ukur jarak, ring sampel, serta peralatan lainnya yang berhubungan 
dengan pemetaan penggunaan lahan dan penghitungan simpanan karbon.

\subsection{Analisis Data}

\section{a. Analisa Perubahan Penggunaan dan Lahan}

Pengolahan data spasial penggunaan lahan dilakukan dengan menerapkan metode pengolahan citra digital (digital image processing) dengan menggunakan Citra Spot 5 tahun 2004, Citra Spot 5 tahun 2009 dan Citra Spot 6 tahun 2014. Setelah dilakukan interpertasi visual terhadap citra, peta yang didapatkan selanjutnya ditumpangsusunkan dengan peta Neraca Tata Guna Tanah Kabupaten Banyuasin skala $1: 25,000$ tahun 2014. Hasil tumpang susun ini selanjutnya ditumpangsusunkan lagi dengan Peta Jenis Tanah Kabupaten Banyuasin skala 1:50,000. Dilakukan pengamatan (ground Check) pada 50 titik tiap-tiap penggunaan lahan.

Analisa perubahan luas penggunaan lahan tahun 2004-2014 di wilayah penelitian dilakukan dengan tumpang susun peta penggunaan dan penutupan lahan tahun 2009 dengan tahun 2004 dan tahun 2014 dengan tahun 2009.

\section{b. Analisa Simpanan dan Perubahan simpanan Karbon}

Simpanan karbon dan perubahannnya dianalisa dari 381 titik sampel penggunaan. Pada tiap-tiap titik dilakukan pengamatan dengan 2 ulangan. Plot pengamatan yang digunakan mengacu pada Standar Nasional Indonesia (SNI) (7724:2011) tentang pengukuran dan penghitungan simpanan karbon.

Penghitungan biomassa diatas permukaan tanah berupa pancang, tiang dan pohon menggunakan persamaan allometrik. Penghitungan biomassa semai dilakukan dengan memanen dan menimbang berat panen. Biomassa nekromassa untuk pohon mati dihitung dengan persamaan allometrik dikalikan faktor koreksi dari tingkat keutuhan pohon mati, sedangkan nekromasa berupa ranting, pelepah dan bagian pohon mati lainnya langsung ditimbang beratnya di lokasi dan sebanyak 300 gram diambil untuk diamati berat keringnya. Penghitugan biomassa serasah dengan mengumpulkan serasah dalam plot pengamatan, menimbang berat total serasah, mengambil sebanyak sebanyak 300 gram untuk dilakukan pengamatan berat kering di laboratorium. Penghitungan biomassa simpanan di bawah tanah menggunakan persamaan allometrik (Brown, 1997). Penghitungan C organik tanah dilakukan dengan mengambil contoh tanah pada kedalaman 0-30 cm dikompositkan (bulked) dan kandungan $\mathrm{C}$ organik tanah ditetapkan dalam persen dengan metode Walkley dan Black. Penghitungan kandungan karbon tersimpan pada masing-masing penggunaan lahan dengan mengalikan berat biomassa dengan 0.48 (Brown 1997).

\section{c. Neraca Karbon}

Penghitungan perubahan tampungan karbon tahun 2004-2009, 2009-2014 menggunakan metode perubahan tampungan karbon (stock difference), yaitu dengan cara memperkirakan perbedaan tampungan karbon pada suatu selang waktu, Metode ini digunakan juga oleh Van Noordwijk et al. (2010). Prinsip yang digunakan, yaitu jika tidak berubah dalam periode waktu tertentu, diasumsikan tidak terjadi perubahan simpanan karbon dan lahan yang mengalami perubahan penggunaan akan mengalami perubahan simpanan karbon. Jumlah karbon yang dikandung oleh penggunaan lahan awal dikurangi dengan tampungan karbon penggunaan lahan berikutnya. Untuk memperkirakan perubahan tampungan karbon tersebut terdapat pada persamaan berikut (IPCC, 2007)

$$
\Delta C=\frac{(C t 2-C t 1)}{(t 2-t 1)}
$$

dimana :

$\Delta \mathrm{C}$ :Tampungan karbon pada skala bentang lahan $\left(\right.$ ton $\left.\mathrm{th}^{-1}\right)$,

Ct1 : Tampungan karbon pada waktu 11 (ton $\left.t^{-1}\right)$

$\mathrm{Ct} 2$ : Tampungan karbon pada waktu $\mathrm{t} 2\left(\right.$ ton $\left.\mathrm{th}^{-1}\right)$

\section{d. Emisi dan Serapan $\mathrm{CO}_{2}$}

Penghitungan emisi dan serapan $\mathrm{CO}_{2}$ dilakukan dengan menghitung simpanan karbon (carbon stock) pada waktu tertentu (stock defference method). Perbedaan tampungan karbon pada waktu yang berbeda akan menunjukkan terjadinya emisi atau penambahan stok (sink) (Wibowo et al., 2010). Pada prinsipnya penghitungan emisi dan serapan $\mathrm{CO}_{2}$ karena perubahan penggunaan lahan yaitu jika perubahan penggunaan lahan dari yang lebih banyak karbon menjadi penggunaan yang lebih sedikit karbon disebut emisi (selisih nilai negatif). Jika perubahan dari penggunaan lahan dari sedikit karbon menjadi lebih banyak karbon disebut serapan (selisih nilai positif). Sedangkan tidak terjadi perubahan lahan maka dianggap nol (tidak terjadi emisi maupun serapan). Untuk mendapatkan besarnya perubahan emisi dan serapan tiap-tiap tahun dengan membagi perubahan dengan persamaan berikut:

$$
E S t={ }_{t 2-t 1}^{\Delta \Sigma t 2-t 1}
$$

dimana

ESt :Emisi/serapan pertahun (ton $\mathrm{CO}_{2} \mathrm{ha}^{-1} \mathrm{th}^{-1}$ ), $\Delta \Sigma \mathrm{t} 2-\mathrm{t} 1$ :Beda emisi dan serapan $\mathrm{CO}_{2}$ dari $\mathrm{t} 1-\mathrm{t} 2$ (ton $\mathrm{CO}_{2} \mathrm{ha}^{-1} \mathrm{th}^{-1}$ )

Untuk menghitung emisi/serapan $\mathrm{CO}_{2}$ berdasarkan perubahan tampungan karbon dengan mengkonversi berat molekul karbon yang diemisikan dan diserap dengan berat molekul $\mathrm{CO}_{2}$. Persamaan yang digunakan sebagai berikut.

dimana

$$
\mathrm{WCO}_{2}=\mathrm{WIC} * 3.67
$$

$\mathrm{WCO}_{2}$ : Banyaknya $\mathrm{CO}_{2}$ yang diserap (ton)

WIC :Total kandungan karbon penggunaan penutupan lahan (ton ha-1) 3,67: Angka

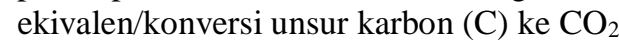
(massa atom $\mathrm{C}=12$ dan $0=16, \mathrm{CO}_{2}=$ $(1 \times 12)+(2 \times 16)=44 ;$ konversinya $=(44: 12)$ $=3.67$. 


\section{Hasil dan Pembahasan}

\subsection{Perubahan Penggunaan dan Penutupan Lahan}

Penggunaan lahan di Kabupaten Banyusin tahun 2004, 2009 dan 20014 disajikan pada Gambar 2, 3 dan 4. Sedangkan perubahan luas masing-masing penggunaan lahan dari tahun 2004, 2009 dan 2014 disaajikan pada Gambar 5.

Gambar 5 menunjukkan, selama tahun 2004-2009 dinamika perubahan penggunaan lahan di Kabupaten Banyuasin cukup besar. Terjadi perubahan luas 75.819 ha pada 14 tipe penggunaan lahan. Penambahan luas didominasi oleh karet monokultur gambut, sawit, belukar rawa dan karet monokultur. Pengurangan luas tipe penggunan lahan terjadi pada 11 penggunaan, didominasi oleh sawah $1 \mathrm{x}$, semak belukar, hutan rawa sekunder, hutan mangrove sekunder, semak belukar gambut dan hutan rawa sekunder gambut.
Tahun 2009-2014 terjadi perubahan penggunaan lahan di Kabupaten Banyuasin seluas 32.576 ha pada 11 tipe penggunaan lahan, Penambahan luas didominasi oleh semak belukar gambut, semak belukar, dan monokultur gambut. Sedangkan pengurangan luas tipe penggunaan lahan sebanyak 11 penggunaan yang didominasi oleh sawah $1 \mathrm{x}$, semak belukar, hutan rawa sekunder, hutan mangrove sekunder, semak belukar gambut dan hutan rawa sekunder gambut.

\subsection{Neraca Karbon}

Neraca karbon yang terbentuk karena perubahan penggunaan lahan sebagaimana disajikan pada Gambar 6. Sedangkan hasil analisa sumber perubahan penggunaan lahan yang menyebabkan pergerakan neraca karbon disajikan sebagaimana Gambar 7 dan 8 .

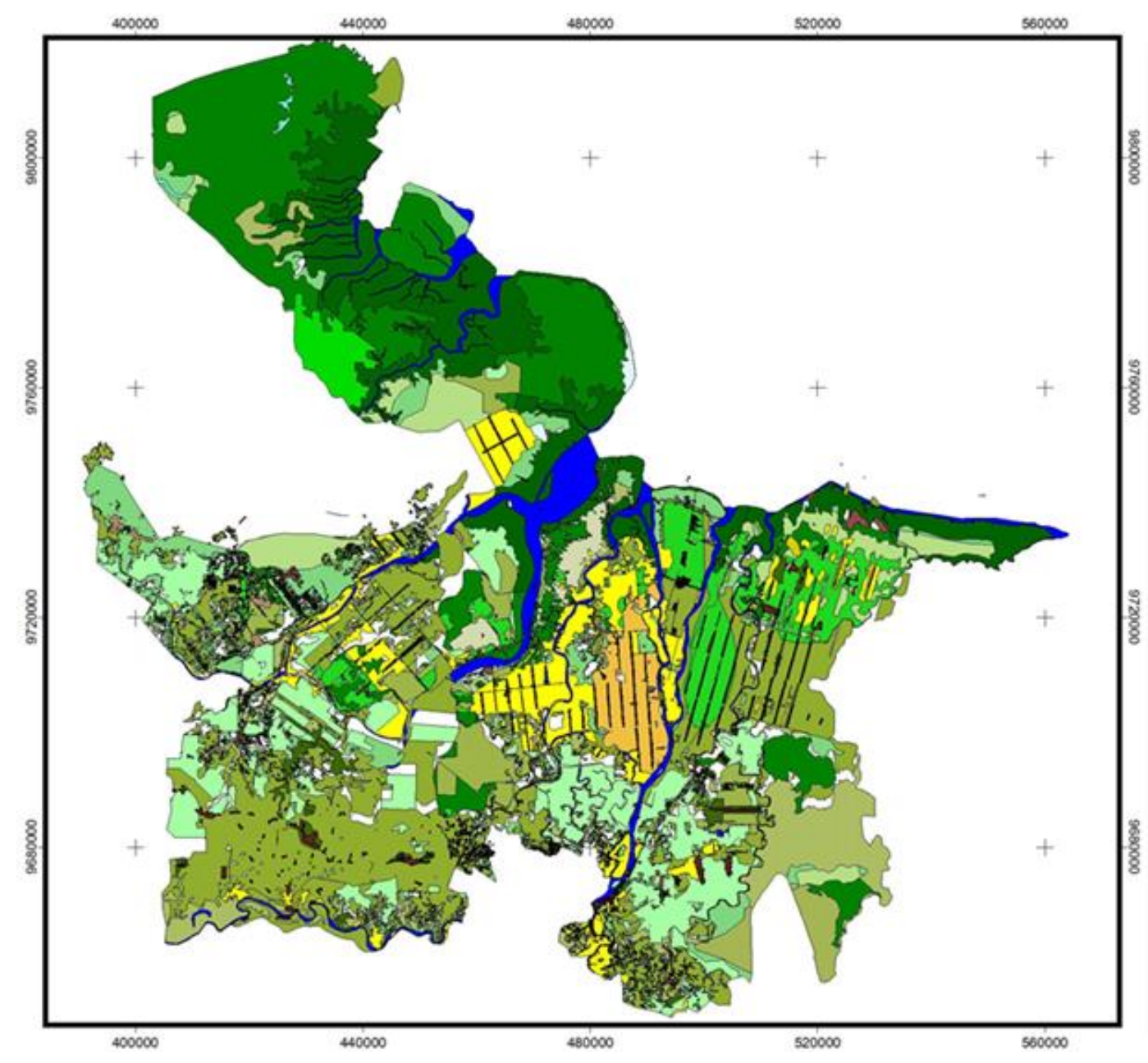

Gambar 2. Peta Penggunaan lahan tahun 2004 


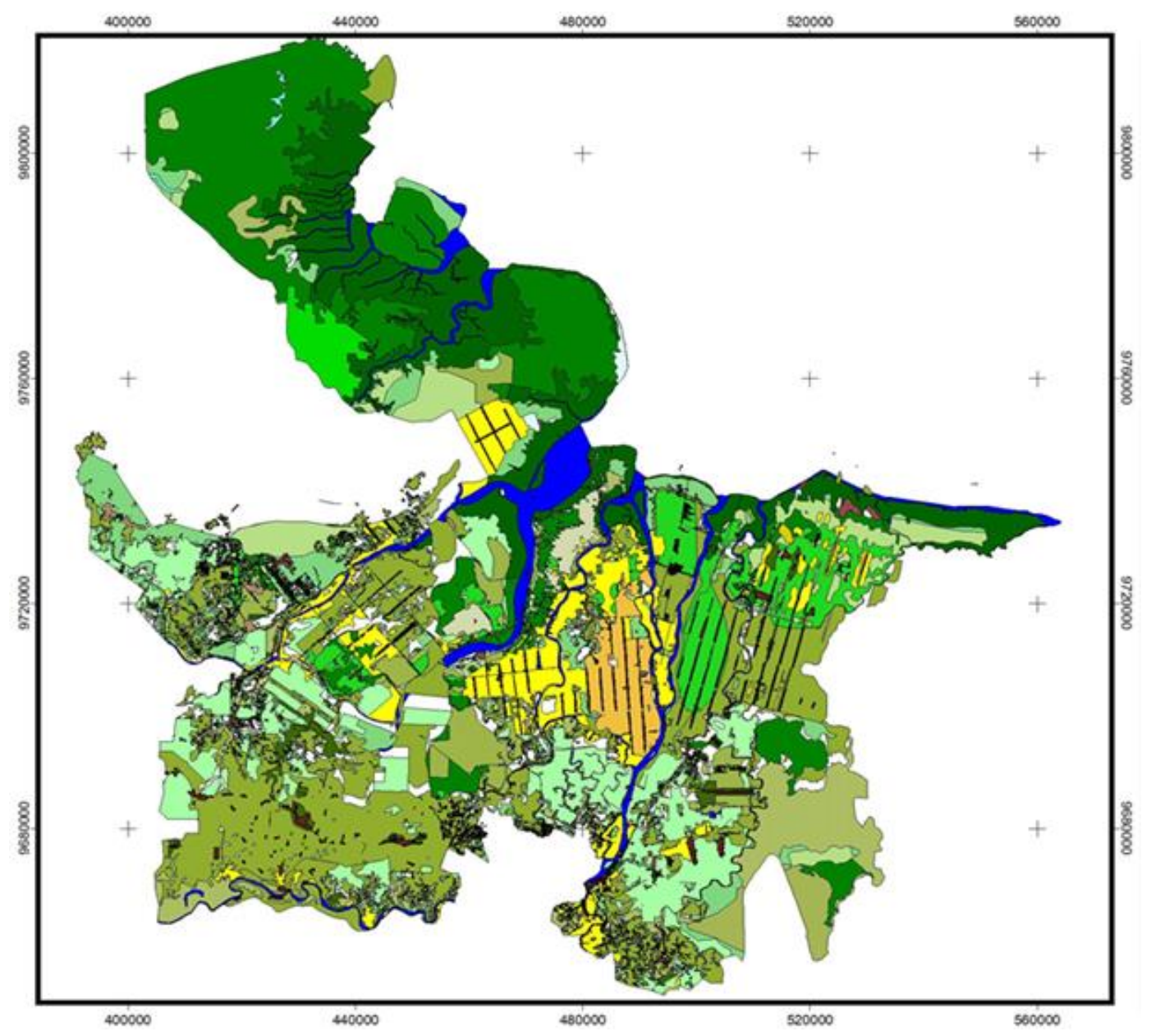

Gambar 3. Peta Penggunaan lahan tahun 2009

Selama tahun 2004-2014 terjadi kehilangan karbon di wilayah penelitian sebanyak 22,033,277 ton dengan rata-rata pertahun sebanyak 2,203,327 ton. Tahun 2004-2009 neraca karbon bergerak ke arah negatif dengan kehilangan karbon sebesar 10,616,604 ton yang berasal dari tampungan karbon di atas permukaan tanah, tampungan nekromasa, tampungan serasah dan tampungan bawah permukaan tanah. Disisi lain di tahun 2004-2009 terjadi penambahan C organik tanah sebanyak 3,515,518 ton. Total kehilangan karbon dari sistem terestrial daratan Kabupaten Banyuasin tahun 2004-2009 sebesar 7,101,086 ton.

Gambar 7 menunjukkan bahwa perubahan penggunaan lahan yang menyebabkan kehilangan karbon adalah berkurangnya luas hutan mangrove primer dan hutan mangrove sekunder. Perubahan ini tentunya akan membawa dampak yang cukup besar terhadap pengurangan karbon. Karena simpanan karbon yang dimilki hutan mangrove primer maupun hutan mangrove sekunder sangat besar. Tampungan dengan simpanan karbon terbesar pada hutan mangrove ini adalah pada tampungan karbon di bawah tanah. Penelitian yang dilakukan Donoto et al. (2011) bahwa hutan mangrove memiliki simpanan karbon di bawah tanah lima kali lebih banyak jika dibandingkan dengan simpanan karbon di atas permukaan tanah.

Tidak hanya kehilangan karbon yang terjadi di sistem terestrial Kabupaten Banyuasin tahun 2004-
2009. Penambahan karbon juga terjadi karena adanya perubahan penggunaan lahan menjadi semak belukar, hutan rawa sekunder gambut, semak belukar gambut dan belukar rawa.

Tahun 2009-2014 kehilangan karbon dari sistem terestrial Kabupaten Banyuasin lebih banyak jika dibandingkan dengan tahun 2004-2009, yaitu sebanyak $13,564,642$ ton, yang bersumber dari tampungan karbon di atas permukaan tanah, tampungan nekromasa, tampungan serasah dan tampungan bawah permukaan tanah. Kehilangan karbon yang berasal dari C organik tanah sebanyak 1,367,549 ton. Total kehilangan karbon pada periode ini adalah sebanyak $14,932,191$ ton.

Selama tahun 2004-2014 terjadi penurunan karbon pada tampungan di atas permukaan tanah, nekromassa, serasah dan karbon di bawah tanah sebanyak 13,564,642 ton. Tampungan $\mathrm{C}$ organik juga menurun sebanyak $1,367,549$ ton.

Dalam pengendalian emisi dan serapan $\mathrm{CO}_{2}$ di suatu wilayah, intinya adalah mengendalikan perubahan vegetasi. Perubahan penggunaan/ penutupan lahan, baik yang disengaja berupa pengaruh antropogenik maupun secara alamiah adalah sangat penting diperhatikan untuk mengupayakan pengendalian perubahan terhadap vegetasi. 


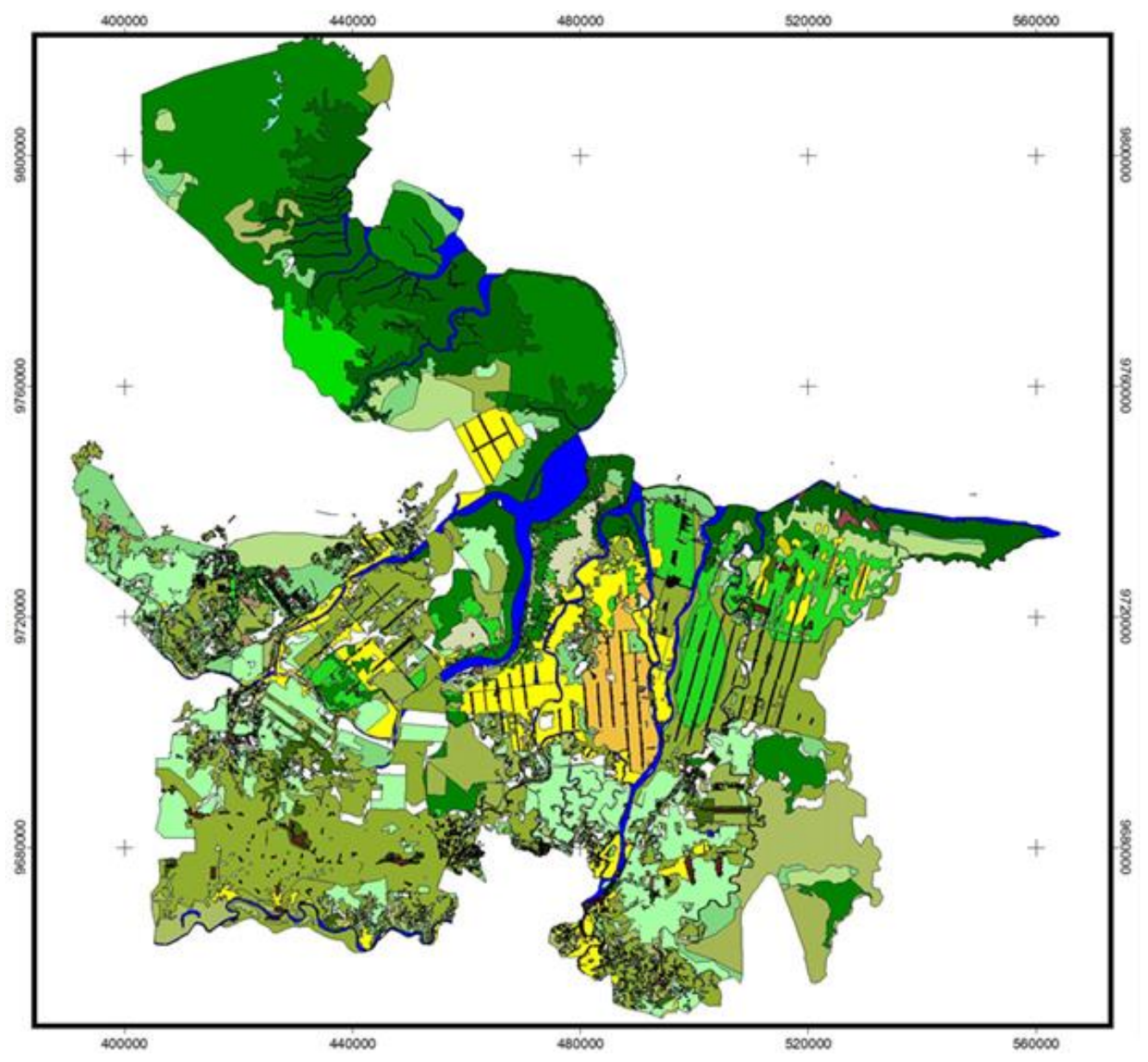

Gambar 4. Peta Penggunaan lahan tahun 2014

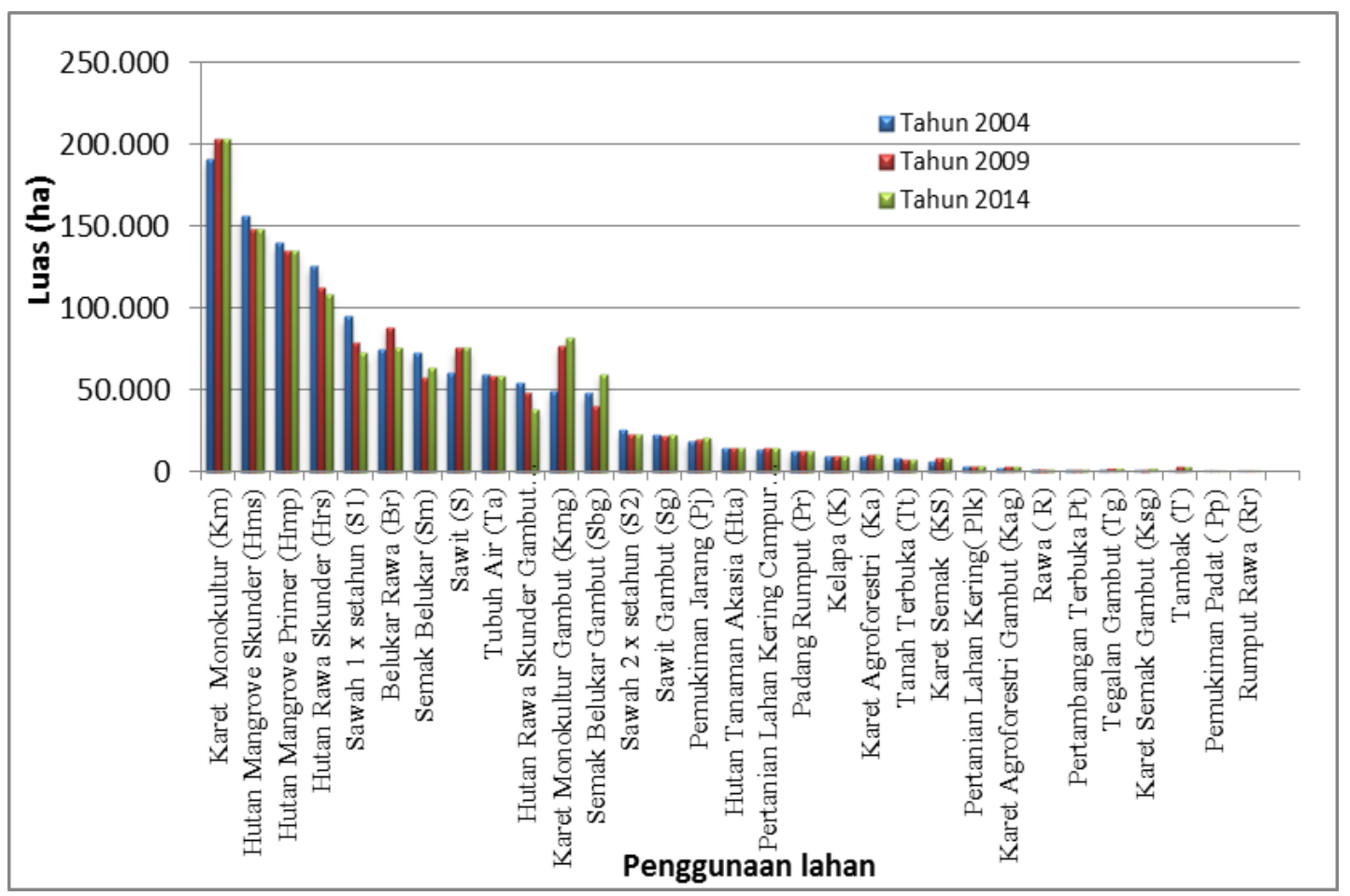

Gambar 5. Perubahan luas penggunaan lahan tahun 2004, 2009 dan 2014 


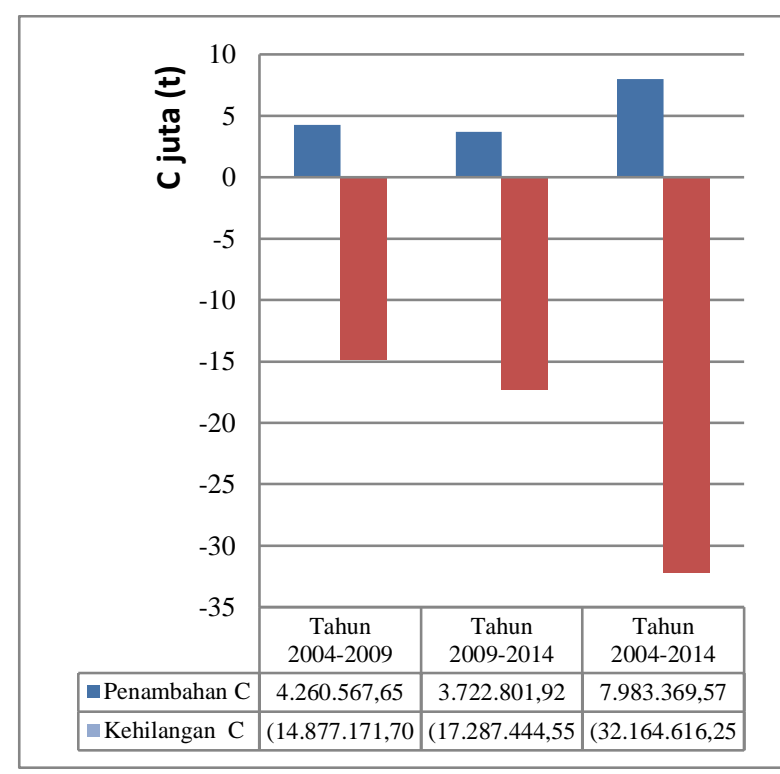

Gambar 6. Neraca karbon Kabupaten Banyuasin tahun 2004-2009, 2009-2014 dan 200-2014

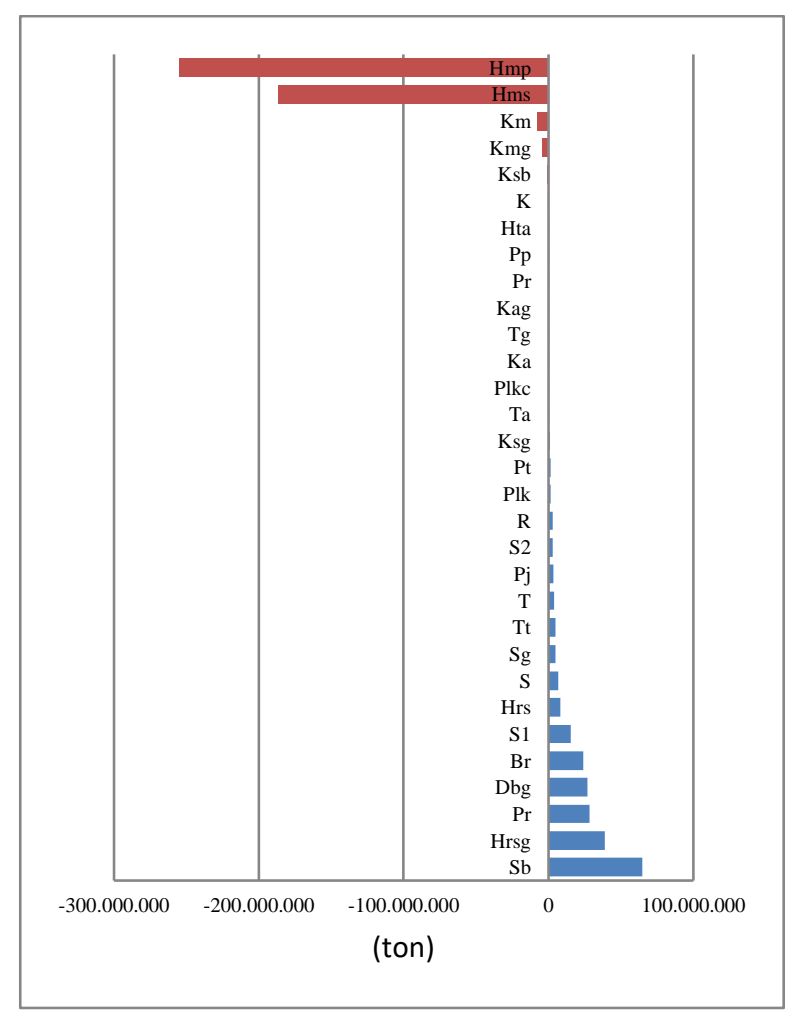

Gambar 7. Sumber penambahan dan kehilangan karbon 2004-2009

Keterangan:

hutan mangrove primer (Hmp), hutan mangrove sekunder (Hms), hutan rawa sekunder (Hrs),hutan tanaman akasia (Hta),semak belukar (Sm), rumput rawa $(\mathrm{Rr})$, belukar rawa $(\mathrm{Br})$, sawit $(\mathrm{S})$, tambak $(\mathrm{T})$, pertanian lahan kering( $\mathrm{Plk})$, pertanian lahan kering campur $(\mathrm{Plkc})$, kelapa $(\mathrm{K})$, pemukiman jarang $(\mathrm{Pj})$, pemukiman padat $(\mathrm{Pp})$, pertambangan terbuka $(\mathrm{Pt})$, rawa $(\mathrm{R})$, padang rumput $(\mathrm{Pr})$, tanah terbuka (Tt), sawah 1 x setahun ( $\mathrm{S} 1)$,sawah 2 x setahun (S2), karet monokultur (Km), karet semak (KS), karet agroforestri (Ka), tubuh air (Ta), sawit gambut ( $\mathrm{Sg}$ ), karet monokultur gambut (Kmg), karet semak gambut (Ksg), karet agroforestri gambut (Kag), hutan rawa sekunder gambut (Hrsg), semak belukar gambut ( $\mathrm{Sbg})$, tegalan gambut $(\mathrm{Tg})$
Dari penelitian ini menunjukkan bertambahnya luas perkebunan sawit dan karet tidak serta merta menimbulkan emisi $\mathrm{CO}_{2}$. Perubahan semak belukar, padang rumput, tegalan, sawah $1 \mathrm{x}$ setahun, rumput rawa menjadi karet dan sawit justru bernilai positif dalam meningkatkan simpanan karbon di sistem terestrial darat dan sebagai sumber serapan $\mathrm{CO}_{2}$ atmosfer yang efektif.

Dinamika kehilangan karbon di Kabupaten Banyuasin tahun 2004-2014 menunjukkan bahwa kehilangan karbon lebih besar jika dibandingkan dengan penambahan karbon. Meskipun perubahan tipe penggunaan lahan yang dapat menambah karbon lebih banyak, namun belum mampu mengimbangi kehilangan karbon yang terjadi. Hal ini disebabkan oleh berkurangnya luas hutan mangrove primer dan hutan mangrove sekunder yang memiliki tampungan karbon sangat besar setiap hektarnya.

Perubahan simpanan karbon di Kabupaten Bayusain tidak terlepas dari pengaruh keberadaan vegetasi. Di suatu sisi vegetasi sebagai sumber satu-satunya karbon pada sistem terestrial, di sisi lain juga berperan menyerap $\mathrm{CO}_{2}$ dari atmosfer untuk menghasilkan biomassa. Tampungan karbon diatas permukaan tanah, tampungan nekromassa, tampungan serasah, tampungan bawah permukaan tanah dan tampungan $\mathrm{C}$ organik tanah semuanya sangat tergantung pada input $\mathrm{C}$ ke dalam dan keluar sistem tersetrial yaitu vegetasi.

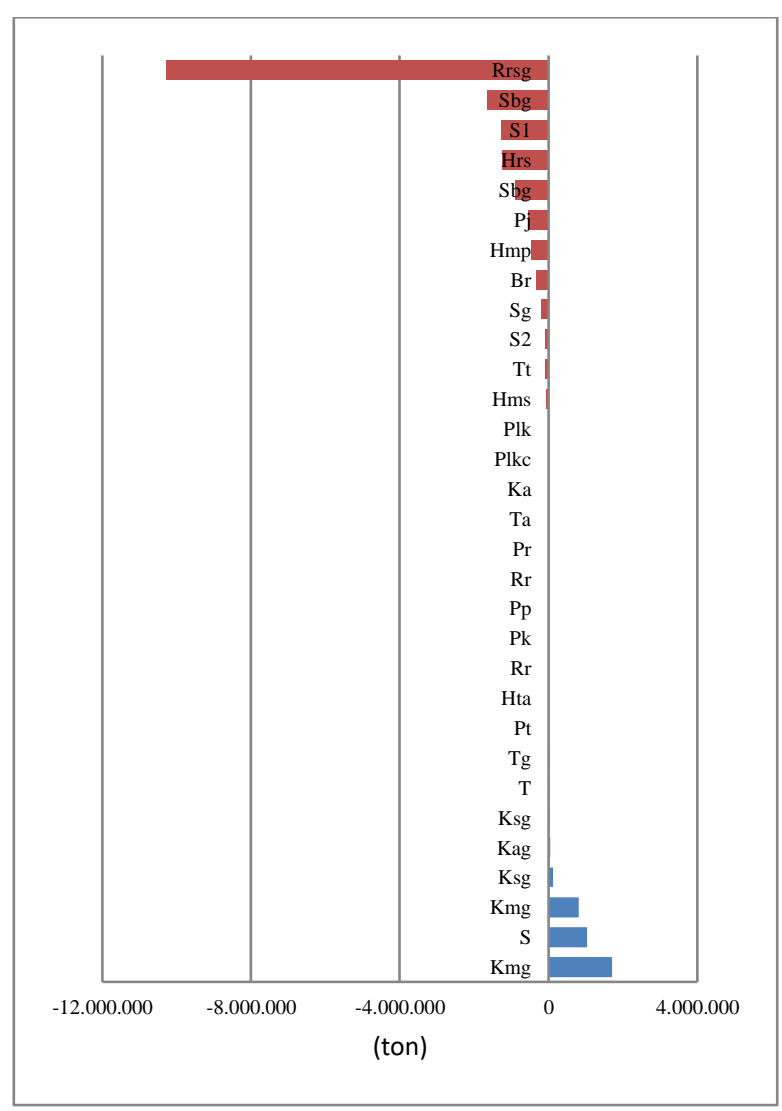

Gambar 8. Sumber penambahan dan kehilangan karbon tahun 2009-2014 
Perubahan penggunaan lahan untuk kegiatan budidaya perkebunan dianggap cukup efektif dalam mempertahankan simpanan karbon di darat. Hal ini disebabkan tanaman-tanaman perkebunan memiliki biomassa yang cukup besar sehingga karbon yang tertahan akan lebih banyak. Disamping itu kegiatan budidaya yang dilakukan sekaligus menyebabkan pengayaan nitrogen melalui pemupukan. Pengayaan nitrogen dapat menyebabkan peningkatan serapan $\mathrm{CO}_{2}$ dari atmosfer.

Tahun 2004-2009 perubahan penggunaan /penutupan lahan yang terjadi kearah negatif (kehilangan) sebesar 10,616,604 ton yang berasal dari tampungan karbon di atas permukaan tanah, tampungan nekromasa, tampungan serasah dan tampungan bawah permukaan tanah. Disisi lain terjadi penambahan $\mathrm{C}$ organik tanah sebanyak 3,515,518 ton. Kehilangan bersih karbon tahun 2004-2009 sebesar 7,101,086 ton

Kehilangan karbon dari sistem tersetrial Kabupaten Banyuasin tahun 2009-2014 sebanyak 13,564,642 ton, yang bersumber dari tampungan diatas permukaan tanah, tampungan nekromasa, tampungan serasah dan tampungan bawah permukaan tanah. Kehilangan karbon yang berasal dari $\mathrm{C}$ organik tanah sebanyak 1,367,549 ton. Total kehilangan karbon pada periode ini adalah sebanyak 14,932,191 ton.

Jumlah kehilangan karbon tahun 2004-2014 sebanyak 22,033,277 ton dari sistem terestrial Kabupaten Banyuasin belum dapat dikatagorikan kehilangan yang besar ataupun kecil. Kehilangan tersebut terjadi selama 10 tahun pada luas wilayah penelitian 1,281,550 ha. Jika dihitung perbandingan antara jumlah karbon yang hilang dengan jumlah karbon total yang dimiliki oleh wilayah penelitian, maka pengurangannya selama 10 tahun sebanyak $4.48 \%$ atau rata-rata per tahun terjadi kehilangan karbon sebanyak $0.45 \%$. Persentase kehilangan karbon di dalam suatu wilayah ini tentunya akan lebih penting digunakan untuk menilai perubahan tampungan karbon diwilayah daripada hanya memperhatikan berapa besar jumlah emisinya.

Simpanan karbon di Kabupaten Banyuasin cukup besar dengan rata-rata perhektar sebanyak 338.28 ton, dengan persentase kehilangan sebanyak $0.45 \%$ per tahun. Perbandingan antara jumlah simpanan karbon perhektar dibandingkan dengan persen kehilangan tentunya akan lebih tepat digunakan dalam menilai status karbon suatu wilayah.

\subsection{Emisi dan Serapan $\mathrm{CO}_{2}$}

Emisi dan Serapan $\mathrm{CO}_{2}$ selama tahun 2004-2014, tahun 2004-2009 dan 2009-2014 disajikan pada Gambar 9. Gambar 10 menyajikan perubahan penggunaan lahan yang menghasilkan emisi dan serapan $\mathrm{CO}_{2}$ selama tahun 2004-2009. Gambar 11 menyajikan perubahan penggunaan/ penutupan lahan yang menghasilkan emisi dan serapan $\mathrm{CO}_{2}$ selama tahun 2009-2014.

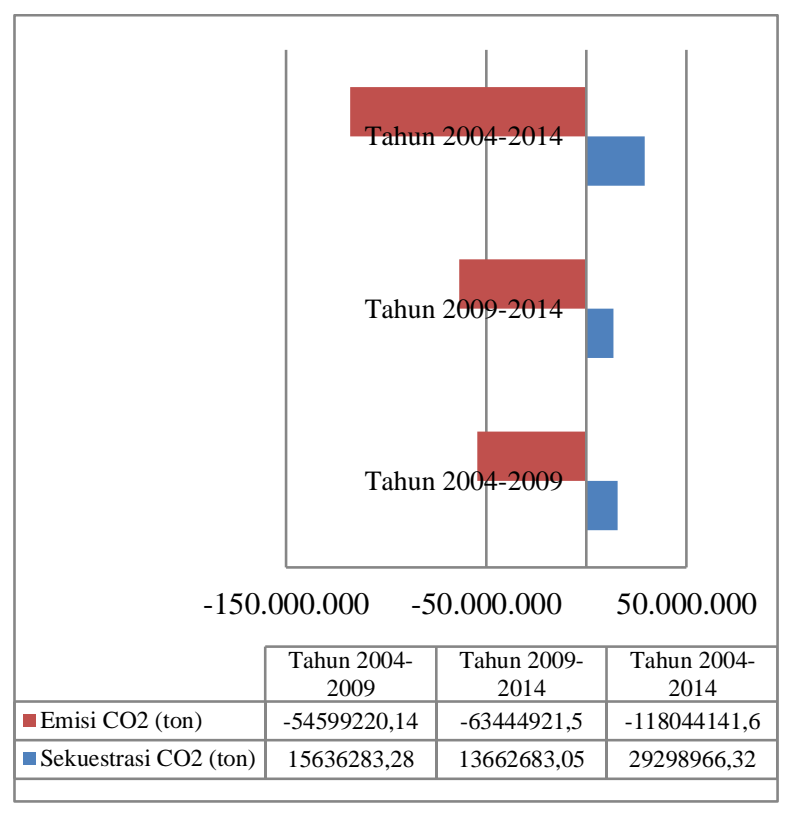

Gambar 9. Emisi dan serapan $\mathrm{CO}_{2}$ karena perubahan penggunaan lahan di Kabupaten Banyuasin tahun 20042014

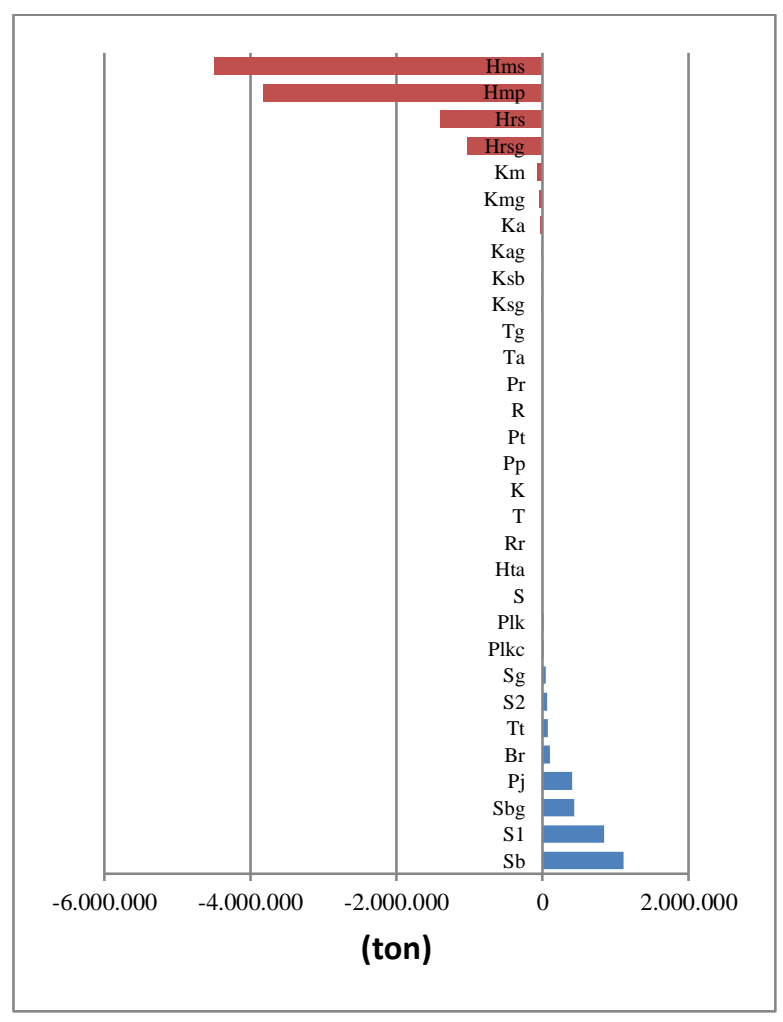

Gambar 10. Sumber emisi dan serapan $\mathrm{CO}_{2}$ di Kabupaten Banyuasin tahun 2004-2009

Selama tahun 2004-2014 terjadi emisi $\mathrm{CO}_{2}$ akibat perubahan penggunaan lahan. Namun juga terjadi serapan meskipun jumlah emisi jauh lebih besar dari pada jumlah serapan. Terjadi Serapan $\mathrm{CO}_{2}$ sebanyak 29,298,966 ton dari atmosfer ke wilayah terestrial Kabuapeten Banyuasin. Emisi $\mathrm{CO}_{2}$ terjadi sebanyak $118,044,141$ ton. Emisi bersih yang terjadi sebesar $88,745,175$ ton, dengan $8,974,517$ ton per tahun. 
Jumlah emisi di wilayah Kabupaten Banyuasin adalah 7 ton $\mathrm{ha}^{-1} \mathrm{th}^{-1}$ selama tahun 2004-2014.

Gambar 11 menunjukkan bahwa selama tahun 2009-2014 perubahan lahan yang dominan menghasilkan emisi $\mathrm{CO}_{2}$ adalah perubahan lahan hutan mangrove sekunder, hutan mangrove primer, hutan rawa sekunder dan hutan rawa sekunder gambut. Sedangkan perubahan penggunaan lahan yang menyebabkan serapan $\mathrm{CO}_{2}$ adalah semak belukar, sawah 1x setahun, semak belukar gambut dan pemukiman jarang.

Tahun 2009-2014 juga terjadi emisi dan serapan $\mathrm{CO}_{2}$. Perubahan penggunaan lahan yang menghasilkan emisi adalah hutan rawa sekunder gambut, hutan mangrove sekunder, hutan mangrove primer dan hutan rawa sekunder. Sedangkan perubahan penggunaan lahan yang menghasilkan serapan adalah karet monokultur gambut, sawit dan karet monokultur.

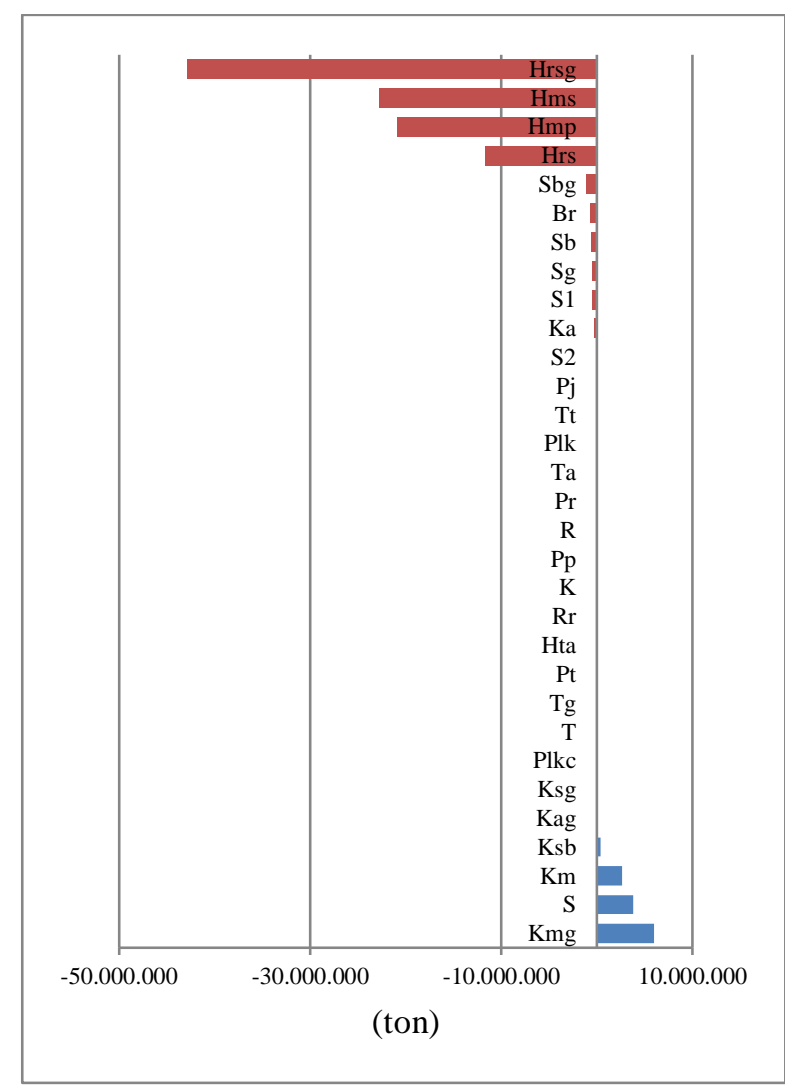

Gambar 11. Sumber emisi dan serapan $\mathrm{CO}_{2}$ di Kabupaten Banyuasin tahun 2009-2014

Terjadinya mekanisme emisi dan serapan dikendalikan oleh siklus karbon yang terjadi di wilayah penelitian. Ketersediaan $\mathrm{CO}_{2}$, suhu, dan interaksinya berpengaruh langsung atau tidak langsung terhadap siklus $\mathrm{C}$ di dalam tanah. Ketersediaan $\mathrm{CO}_{2}$ secara langsung memacu proses respirasi sebagai bahan dasar. Meningkatnya suhu secara langsung memacu proses dekomposisi, dengan mempercepat aktivitas enzim dan reaksi-reaksi kimia. Di samping itu peningkatan $\mathrm{CO}_{2}$ secara tidak langsung mempengaruhi kecepatan dekomposisi bahan organik. Hal ini sejalan dengan hasil penelitian Jauhiainen et al. (2001) bahwa pada tanah tanpa vegetasi, emisi $\mathrm{CO}_{2}$ menurun dengan meningkatnya kelembaban, hal ini terkait dengan rendahnya aktivitas bakteri aerobik dalam memproduksi $\mathrm{CO}_{2}$ dan lambatnya perubahan gas dalam kondisi tergenang.

Hasil penelitian ini menunjukkan bahwa perubahan penggunaan lahan telah menyebabkan terjadi emisi dan serapan $\mathrm{CO}_{2}$. Penyebab utama emisi di wilayah penelitian adalah perubahan penggunaan lahan hutan rawa sekunder gambut, hutan mangrove sekunder, hutan mangrove primer, hutan rawa sekunder. Sedangkan serapan dominan disebabkan adanya perubahan penggunaan lahan karet monokultur gambut, perkebunan sawit, karet monokultur dan semak belukar

Emisi $\mathrm{CO}_{2}$ selain disebabkan oleh berubahnya tampungan karbon di atas permukaan tanah, tampungan nekromasa, tampungan serasah, tampungan di bawah permukaan tanah, juga disebabkan oleh kehilangan dan penambahan $\mathrm{C}$ organik tanah, hasil analisa menunjukkan juga terjadi emisi yang bersumber dari $\mathrm{C}$ oranik tanah, yaitu sebanyak $7,883,048$ ton selama 2004-2014, atau rata-rata per tahun sebanyak 788,304 ton. Jika dikonversi dalam hektar maka di wilayah Kabupaten Banyuasin terjadi emisi karbon dari C organik organik tanah 0.61 ton ha ${ }^{1} \mathrm{th}^{-1}$.

Dalam mempertahankan simpanan karbon di wilayah Kabupaten Banyusin dapat dilakukan dengan menekan perubahan penggunaan lahan yang memiliki simpanan karbon lebih tinggi menjadi penggunaan lahan yang lebih rendah. Sedangkan untuk mempertahankan dan menambah simpanan karbon diperlukan upaya sebaliknya.

\section{Kesimpulan}

Selama tahun 2004-2014 neraca karbon berbasis penggunaan lahan di Kabupaten Banyuasin bersifat negatif, terjadi kehilangan karbon sebanyak 22,033,277 ton dengan rata-rata kehilangan karbon pertahun sebanyak 2,203,327 ton. Rata-rata simpanan karbon perhektar 338.28 ton, dengan persentase kehilangan $0.45 \%$ per tahun.

Terjadi serapan $\mathrm{CO}_{2}$ sebanyak 29,298,966 ton dan emisi sebanyak $118,044,141$ ton, sedangkan emisi bersih sebanyak 88,745,175 ton. Rata-rata emisi $\mathrm{CO}_{2}$ yang bersumber dari tampungan karbon di atas permukaan tanah, nekromassa, serasah dan karbon di dalam tanah sebanyak 7 ton $\mathrm{ha}^{-1} \mathrm{th}^{-1}$, sedangkan emisi dari C organik tanah sebanyak 0.61 ton $\mathrm{ha}^{-1} \mathrm{th}^{-1}$.

Perubahan penggunaan lahan penyumbang emisi $\mathrm{CO}_{2}$ terbanyak di wilayah Kabupaten Banyuasin secara berurutan adalah hutan rawa sekunder gambut, hutan mangrove sekunder, hutan mangrove primer dan hutan rawa sekunder. Sedangkan sumber serapan $\mathrm{CO}_{2}$ adalah perubahan karet monokultur gambut, perkebunan sawit,karet monokultur dan semak belukar. 


\section{Daftar Pustaka}

[1] Brown, S., 1997. Estimating Biomass and Biomass Change of Tripocal Forest. FAO Forestry Paper 134.

[2] Donato, C.D., J. Kauffman, B. Murdiyarso, S. Kurnianto, M. Stidham, dan M. Kanninen, 2011. Mangroves among the most carbon rich forests in the tropics. Nature Geoscience. 4, pp. 293-297.

[3] Duiker, S.W. and R. Lal, 2000. Carbon budget study using $\mathrm{CO} 2$ flux measurements from a no till system in central Ohio. Soil \& Tillage Research. 54, pp. 21-30.

[4] Hairiah, K., R.U. Sri, L. Betha, dan Meine van Noordwijk, 2004. Neraca Hara dan Karbon dalam Sistem Agroforestri. Bahan Ajaran Agroforestri 6. World Agroforestry Centre ICRAF, SEA Regional Office. Bogor.

[5] Indonesian National Standard, 2011, "Ground Based Forest Carbon Accounting”. Indonesian National Standard Agency. 7724:2011, Jakarta.

[6] IPCC, 1997. Revised 1996 IPCC Guidelines for National Greenhouse Gas Inventories. Volume 1: Reporting Instructions. Intergovernmental Panel on Climate Change.

[7] IPCC, 2007, "Climate Change 2007: Synthesis Report. Contribution of Working Groups I, II and III to the Fourth Assess-ment Report of the Intergovernmental Panel on Climate Change" [Core Writing Team, Pachauri, R.K. and Reisinger, A. (eds.)]. IPCC, Geneva, Switzerland, 104 pp.

[8] Jauhiainen, J., J. Heikkinen, P.J. Martikainen, H. Vasander, 2001. $\mathrm{CO}_{2}$ and $\mathrm{CH}_{4}$ fluxes in pristine peatswamp forest and peatland converted to agriculture in central Kalimantan, Indonesia. International Peat Journal. 11, pp. 43-49.

[9] Jiao, J.G., L.Z. Yang, J.X. Wu, H.Q. Wang, H.X Li, E.C. Ellis, 2010. Land use and soil organic carbon in china's village landscapes. Pedosphere. 20(1), pp. 1-14.

[10] Lal, R., 2008. Carbon sequestration. Philos. Trans. R. Soc. London B. 63, pp. 815-830.

[11] Lasco, R.D., 2004. Forest carbon budgets in southeast asia following harvesting and land cover change. Science in china series 3. 45, pp. 55-56.

[12] Sing, S.K., C.B. Pandey, G.S. Sidhu, D. Sakar, R. Sagar, 2011. Concentration and stock of carbon in the soils affected by land uses and climates in the western Himalaya, India. Catena. 87, pp. 78-89.

[13] Van Noordwijk, M., S. Dewi, N. Khasanah, A. Ekadinata, S. Rahayu, J.P. Caliman, M. Sharma, dan R. Suharto, 2010. Estimating the Carbon Foot print of Biofuel Production from Oil Palm: Methodology and Results from Two Sites in Indonesia. International Conference on Oil Palm and Environment, 23-25 Feb. 2010, Bali, Indonesia.

[14] Wang, Z.P., X.G. Han, L.H. Li, 2008. Effects of grassland conversion to croplands on soil organic carbon in the temperate Inner Mongolia. J. Environ. Manage. 86, pp. 529534.

[15] Wibowo, A., K. Ginoga, F. Nurfatriani, H. Indartik, Dwiprabowo, S. Ekawati, H. Krisnawati, A. Siregar, 2010. REDD+ \& Forest Governance. Pusat Penelitian Sosial Ekonomi dan Kebijakan Kehutanan Kampus Balitbang Kehutanan. 